\title{
AURORA LUQUE, GRECORROMANAS. LIRICA SUPERVIVIENTE DE LA ANTIGÜEDAD CLÁSICA, BARCELONA, PLANETA, 2020
}

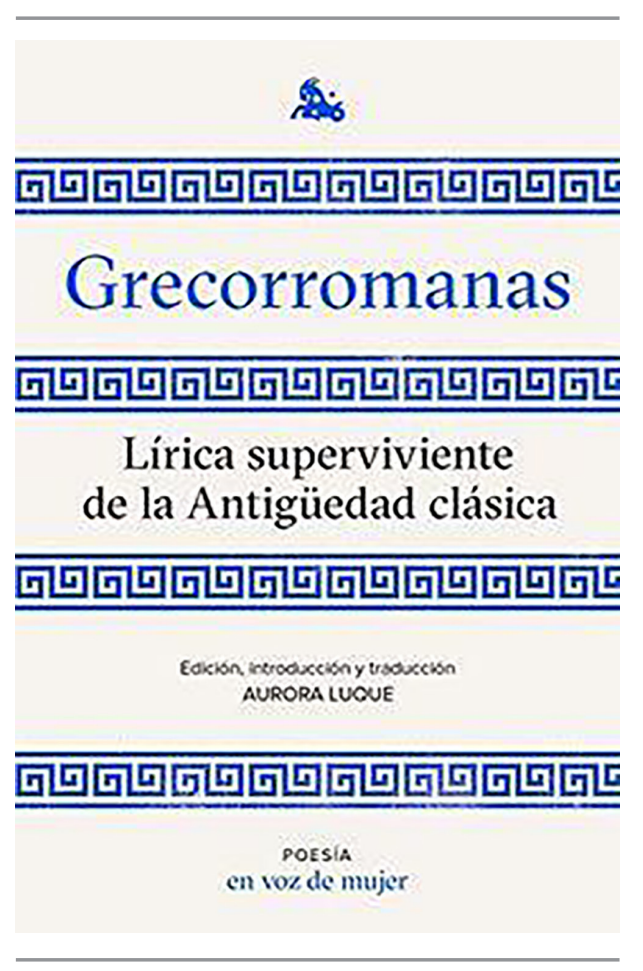

\author{
Abigail Méndez* \\ UNNE-CONICET \\ abigailluzmarinamendez@gmail.com
}

El volumen, organizado en cuatro secciones, además de la introducción, sigue un orden cronológico tradicional: época arcaica, helenística, clásica y romana. En cada período propuesto, presentado con sus diferentes particularidades literarias y culturales, la autora recupera un corpus de poetisas, relegadas al olvido, por una tradición preponderantemente masculina. Su minuciosa investigación da cuenta de una búsqueda casi arqueológica, cuyo objetivo consistió en recuperar nombres y obras e inscribirlos en la historia y la tradición literarias. Al final, incluye una lista de referencias bibliográficas que evidencia la ingente labor realizada, utilizada como insumo instrumental tanto para la elaboración de las traducciones como para la revisión de las obras.

En la "Introducción", después de abordar cuestiones vinculadas con el título de la obra, el canon lírico griego y los temas y formas explorados por las poetisas, incluye el apartado Safo como la iniciadora de la poesía femenina: tópico externo, autoconciencia y sororidad (p. 25), en el que recupera la noción antigua de sororidad como concepto operativo para abordar las obras de las autoras posteriores a Safo. Según el sentido otorgado al término, la sororidad se construye en función de dos vertientes antiguas: por un lado, la filiación instituida por la communis opinio, tanto griega como romana, entre Safo y todas las escritoras femeninas; y, por otro, la conciencia y la autopercepción de pertenecer a la tradición fundada por Safo y considerarse parte de su estirpe. 
En la sección "Época arcaica", la autora asocia el origen de la poesía femenina en Grecia con el nacimiento del pensamiento filosófico, científico y racional. De este período histórico, recupera del olvido nombres y testimonios de mujeres creadoras cuyo ejercicio literario analiza en relación con los distintos géneros y tópicos de la época. Safo es, como explica en la introducción, la primera en crear un ego poético femenino y, a la vez, subversivo: ante la marcada presencia de la poesía épica, que evoca un mundo legendario, protagonizado por héroes, batallas y armas, decide cantar sobre las emociones del cuerpo y los sentimientos personales. El deseo corporal femenino aparece por primera vez materializado en palabras a través de la voz de una mujer, sin mediación ni subordinación masculina alguna, lo que constituye un hecho cultural único. De este período rescata otros nombres, cuyos textos muchas veces son parciales o apenas referidos por algún autor: a Femónoe se le atribuye la invención del hexámetro y del aforismo $\gamma v \tilde{\omega} \theta 1$ $\sigma \varepsilon \alpha v \tau o ́ v$ (gnóthi seautón); de Damófile y Caríxela se menciona que compusieron poesía erótica e himnos a los dioses, a la manera de Safo. A su vez en Esparta existen registros de una rica producción lírica coral cuya ejecución y temática estaban relacionadas con la actividad poética femenina: en el partenio de Alcmán, transmitido por Ateneo, aparece el nombre de Megalóstrata, asociado con la producción de poemas y canciones destinados a festivales, en los que las mujeres participaban activamente. A Muia, mencionada por Luciano, se le atribuye la autoría de himnos a Diana y Apolo. De Cleobulina de Rodas, conocida por ser la hija de uno de los Siete Sabios, Luque resalta el particular valor y significado que debieron adquirir sus poemas compuestos en hexámetro, llamados enigmas o adivinanzas, porque existen huellas de su circulación en el contexto masculino de la época. No tuvo la misma importancia, sin embargo, Erífanis, de quien afirma que fue considerada por Clearco una mera figura legendaria: solo un breve verso se conservó de su lírica, en el que aparecen condensados elementos de la tradición bucólica, explotada más tarde en los idilios de Teócrito y en las églogas virgilianas: las encinas, el lamento al amante y la alocución directa en segunda persona.

En la segunda parte, "Época clásica”, la autora advierte la escasa o inexistente conservación de textos de compositoras atenienses. Dado el valor intelectual desarrollado en la polis y las circunstancias propicias para la producción de poesía, sostiene que resulta sorprendente la falta de documentos que atestigüen la actividad poética femenina. Mientras que en Atenas los ciudadanos se posicionaban como representantes del pensamiento científico, artístico y cultural, las mujeres alcanzaban el mayor período de segregación. A pesar de este silenciamiento, Luque observa que no sucedió lo mismo en otras regiones, como Boecia, el Peloponeso y la isla de Telos, donde sí existen testimonios de creatividad. Rescata del silencio, a través de un minucioso rastreo, a Mirtis, maestra de Corina, cuyo único texto se conservó a través de Plutarco; a Corina, que constituye junto con Safo el acotado grupo de poetisas respetadas en la Antigüedad; a Beo, a quien se le atribuye la autoría del Himno de los delfios, del cual solo se registra un fragmento, transmitido por Pausanias; a Telesila, que compuso sus poemas en un tipo de verso eolio, cuya unidad métrica fue denominada posteriormente por Hefestión, telesileo. De Praxila, resalta la fama alcanzada en los círculos de los poetas atenienses, cuyas obras se enmarcan en dos géneros: el convival y el cultual; de Erina, que evocó tópicos referidos al amor, la amistad y la muerte $y$, especialmente, que su obra se instituye como pionera al cantar, a través del recurso de la memoria poética, heredado de Safo, sobre la infancia como territorio de amor y amistad.

En la sección "Época helenística", la autora repara en los cambios producidos a nivel social y en la influencia que estos tuvieron particularmente en la producción poética de Alejandría. Observa 
que, tras las conquistas de Alejandro Magno, el acervo cultural y la lengua griega alcanzaron su máximo esplendor. En el plano literario también se produjeron alteraciones: desaparecen la tragedia ática y política, y cobra vigencia la comedia burguesa. La lírica, por otra parte, atraviesa un período de renovaciones e innovaciones, dadas, en parte, por las voces femeninas. A pesar de las condiciones propicias, los datos sobre las mujeres vinculadas con la vida poética son nebulosos o nulos; increíblemente, tampoco en la deslumbrante polis, advierte la autora, hay registros de poetas creadoras. En el rastreo de nombres y obras, observa, sin embargo, la presencia de poetas en otras ciudades alejadas del centro de la ebullición cultural; aunque resulta exiguo el número de textos conservados, los versos hallados dan cuenta de la destreza poética tanto en el empleo de la métrica, como en manejo de los tópicos indagados. En Bizancio vivió Moiró, quien cultivó los diferentes géneros poéticos: epigramas, himnos, poemas épicos y líricos, y compuso versos sobre maldiciones o imprecaciones, denominados araí, cuya obra podría representar el origen de una tradición instalada posteriormente. En Tegea se registran escritos de Ánite, de quien se preservaron veinticuatro epigramas (poemas votivos, funerarios y bucólicos, incluidos en la Antología Palatina) y a quien se puede considerar antecesora del género literario más tarde explorado por Teócrito a través del locus amoenus. Ánite es la primera en reunir en una poesía elementos del paisaje bucólico tales como la fuente, la arboleda, la cueva de las ninfas, el pastor y los rebaños. También en Locros compuso Nosis poemas sobre el amor y los placeres sáficos, y se la considera pionera, junto con Safo y Corina, en rechazar y criticar los modelos canónicos. En el apartado Las palabras perdidas (II), nombra a autoras y obras cuyos datos desaparecieron por completo de la tradición, posiblemente poco tiempo después de su composición: Fílina, Pártenis, Mosquina, Glauce, Teano, Aristodama y Alcínoe.

En la última sección del libro, "Época romana", Luque se pregunta sobre los motivos por los que no se gestó en Roma una tradición de mujeres dedicadas a la escritura de poesía, dada la relativa libertad de la que disponían, la efervescencia intelectual de la ciudad y la riqueza de la lengua. De este período expone los exiguos testimonios pertenecientes a las poetisas romanas, de quienes se conservaron breves obras o fragmentos, heredados por medio de una tradición indirecta o, en algunos casos, a través de inscripciones descubiertas en la posterioridad: Melino, compuso un Himno a Roma, de resonancias épicas, transmitido por Estobeo. Este poema, sostiene la autora, se constituye como un hápax poético al comunicar la impresión que producía el surgimiento del nuevo poder político romano sobre el mundo helenístico. Sulpicia es la única autora latina de quien se preservó un significativo y seguro número de textos, incorporados en la colección de elegías denominada Corpus Tibullianum; se sabe que Herennia Prócula escribió un epigrama ecfrástico en honor a Eros y que Claudia Trofime compuso epigramas dedicados a la diosa Hestia; Sulpicia, la satírica, escribió poemas eróticos cien años después que su homónima, pero se destacó, especialmente, por cultivar la sátira política, cuyos matices críticos mostraron la opresión que reinaba en tiempos de Domiciano. De la última pagana, como la nombra Luque, Fabia Aconia Paulina, se conocen treinta versos en los que conmemora dos desapariciones: la de un ser amado y la de la ciudad pagana, aplastada por el cristianismo. Finalmente, también en Roma, en la época de mayor esplendor cultural e imperial, la autora registra palabras perdidas como las de Mermia Timotoe, Cornifia, Hostia y Perila, de quienes solo resuenan sus nombres en textos de otros poetas. 
Grecorromanas representa un necesario aporte a la literatura clásica tanto por su valor documental como literario. La exhaustiva investigación, las rigurosas traducciones de los textos y el análisis realizado en cada sección de este volumen, señalan no solo las dificultades de conservación de las obras escritas por mujeres en la Antigüedad sino también el silencio u ocultamiento a los que fueron sometidos sus textos, en el marco de una tradición literaria constituida, a excepción de Safo, por un canon imperativamente masculino. En esta acción vindicativa de autoras, obras y palabras, también retoma el uso de poetisa, que empleamos en esta reseña, al igual que Luque, para "limpiar el término castellano del peso misógino con que lastró una larga serie de críticos, clérigos, tratadistas y poetas profundamente hostiles a la mera existencia en el idioma de las poetisas" (p. 27).

Con la publicación de este libro, Aurora Luque recupera once siglos de poesía compuesta por escritoras, lo que significa, después de tantos años de ocultamiento y silencio, un reparador acto de justicia poética para la literatura universal.

*Abigail Méndez es Licenciada en Letras (Universidad Nacional del Nordeste), Auxiliar docente en el Seminario Taller de Literatura en las carreras Profesorado y Licenciatura en Letras de la Facultad de Humanidades (UNNE), Becaria Interna Doctoral del CONICET (periodo 2021-2026) e integrante del PI 17H014: "Dimensiones monstruosas de la épica y de sus héroes en Heroidas de Ovidio" (financiado por la Secretaría General de Ciencia y Técnica de la UNNE).

RECIBIDO: 01/04/2021

ACEPTADO: 15/04/2021 